\title{
Effect of addition of organic solvents on properties of the chemically synthesized polyaniline in aqueous solutions
}

\author{
Shuangxi Xing, ${ }^{12}$ Shengyu Jing, ${ }^{1}$ Chun Zhao, ${ }^{1 *}$ Zichen Wang ${ }^{2^{*}}$ \\ 1 State Key Laboratory on Integrated Optoelectronics, Jilin University, Changchun \\ 130012, P.R. China; E-mail:zchun@jlu.edu.cn \\ ${ }^{2}$ College of Chemistry, Jilin University, Changchun, 130012, P. R. China; E-mail: \\ wangzc@mail.jlu.edu.cn
}

(Received: 28 January, 2007; published: May 2, 2007)

\begin{abstract}
In the process of polymerization of aniline in aqueous solution, different kinds or volumes of organic solvents were added. The effects of the organic solvents on the morphology, structure, conductivity and water-dispersity of the resulting polyaniline (PANI) were investigated with the aid of SEM, UV-Vis, FT-IR and Raman spectra and conductivity measurements. The results showed that the weak $\mathrm{H}$-bond interactions between PANI and the solvents might play an important role in forming uniform nanofibers with relatively high conductivity and good waterdispersity. However, excessive addition of organic solvents led to the aggregation of the nanofibers and the corresponding PANI had a bad water-dispersity.

Keywords: polyaniline nanofibers; organic solvents; morphology; conductivity; water-dispersity
\end{abstract}

\section{Introduction}

For over two decades, polyaniline (PANI) as one of the most promising conducting polymers has received considerable research owing to its unique electronic and optical properties and its potential applications in many fields, such as electronic devices and different sensors [1-3]. In recent years, people pay much attention to the synthesis of PANI with nanostructure like nanorods and nanofibers since, for example, the nanostructured PANI sensors showed much higher response than the conventional ones [4-6]. As for the synthesis of nanostructured PANI, many approaches including template and non-template process have been used and developed [7-21]. Among the above methods, a "nanofiber seeding" polymerization as a new typical template approach was reported by Manohar SK et al. for the synthesis of PANI nanofibers. In their experiment, a small amount of nanofibers regardless of their chemical nature was used as "seed" to produce a precipitate with bulk fibrillar morphology [19]. Meanwhile, Huang et al. have reported their investigation on the formation of PANI nanofibers in the last two years [22-26]. They considered the nanofibers were formed at the early stage of the reaction and bulk fibrillar PANI would be obtained if the secondary growth of the particles was suppressed. On the other hand, Wan et al. have reported the effect of hydrogen bond on the formation of PANI nanostructures via using salicylic acid and different carboxylic acids as dopants $[27,28]$. In our early studies on the synthesis of PANI nanofibers, we found uniform PANI nanofibers with relatively high conductivity would be obtained when using PANI/dimethyl sulphoxide (DMSO) solution as seed during the polymerization of aniline [29]. Here, we further found just using organic solvents 
as additive agents would also result in the formation of uniform PANI nanofibers. Though Kan et al. have investigated the effect of ethanol on chemically synthesized PANI nanothread and found different usages of ethanol would result in PANI with different morphology without changing of conductivity [30, 31], few investigations have been reported for the influence of other organic solvents, including DMSO, dimethyl formamide (DMF), tetrahydrofuran (THF) and N-methyl-2-pyrrolidinone (NMP). The effects of the kinds and usages of the organic solvents on the morphology, structure, conductivity and water-dispersity of the resulting PANI have been investigated via the aid of SEM, UV-Vis, FT-IR and Raman spectra and conductivity measurements. The weak $\mathrm{H}$-bond interaction between the organic solvents and PANI was considered as the driving force which affects the morphology and water-dispersity of the resulting PANI.

\section{Results and discussion}

\section{Morphology}

The SEM images of the resulting PANI synthesized in the presence of different kinds of organic solvents are shown in Fig. 1. One can find using DMSO (Fig. 1a) and THF (Fig. 1c) as additive agents led to the formation of PANI nanofibers with the average width of $50 \mathrm{~nm}$ and length of $500 \mathrm{~nm}$, respectively.
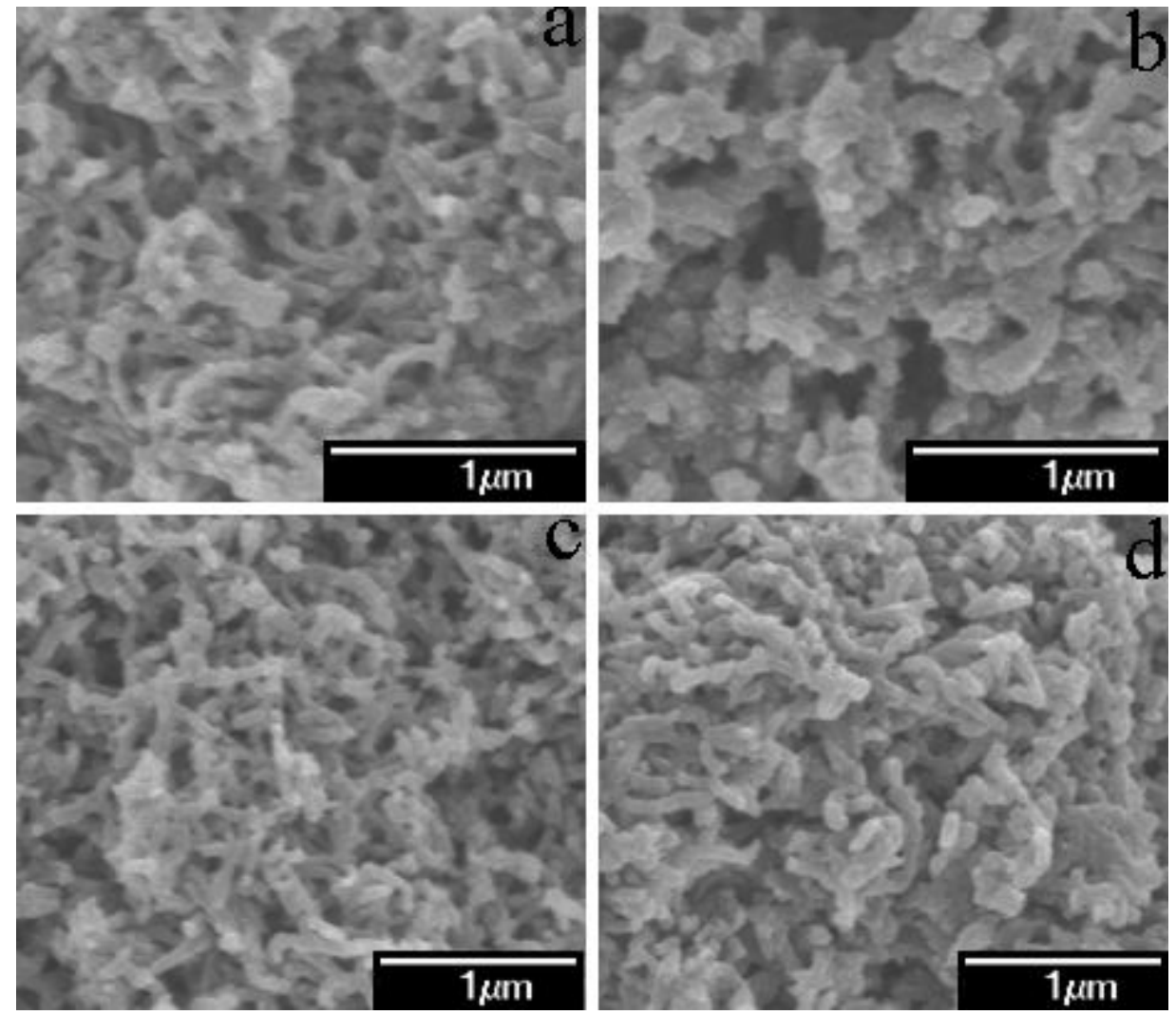

Fig. 1. SEM images of PANI obtained from the systems with different kinds of organic solvents as additives (a. DMSO; b. DMF; c. THF; d. NMP).

However, aggregation can be observed when the polymerization of aniline was carried out in the presence of DMF (Fig. 1b) and NMP (Fig. 1d). In our former experiments we have discussed the effect of the PANI / DMSO solution as seed on 
the formation of PANI nanofibers [29]. Here, we consider the addition of organic solvents may act as another kind of seed during the polymerization process. As we know, all the four kinds of solvents can be partly dissolved in water and aniline oligomers are produced at the beginning of the polymerization. When the organic solvent is added into the reaction system, they help producing and dispersing the oligomers via their weak $\mathrm{H}$-bond interactions with the oligomers. In that way, the following polymerization of aniline is carried out in an ordered direction, which leads to the dispersion of the PANI nanofibers and hence suppresses the second growth of the nanofibers [24]. As for the difference between the PANI obtained from different systems, we think this may be originated from the different properties of the four organic solvents. DMF and NMP are two kinds of organic solvents with stronger base compared with DMSO and THF and they have stronger interaction with PANI, which probably suppresses the good dispersity of the newly formed nanofibers. However, the organic solvents still has effect on the production of PANI nanofibers compared with the product processed by conventional method (Fig. 2d).
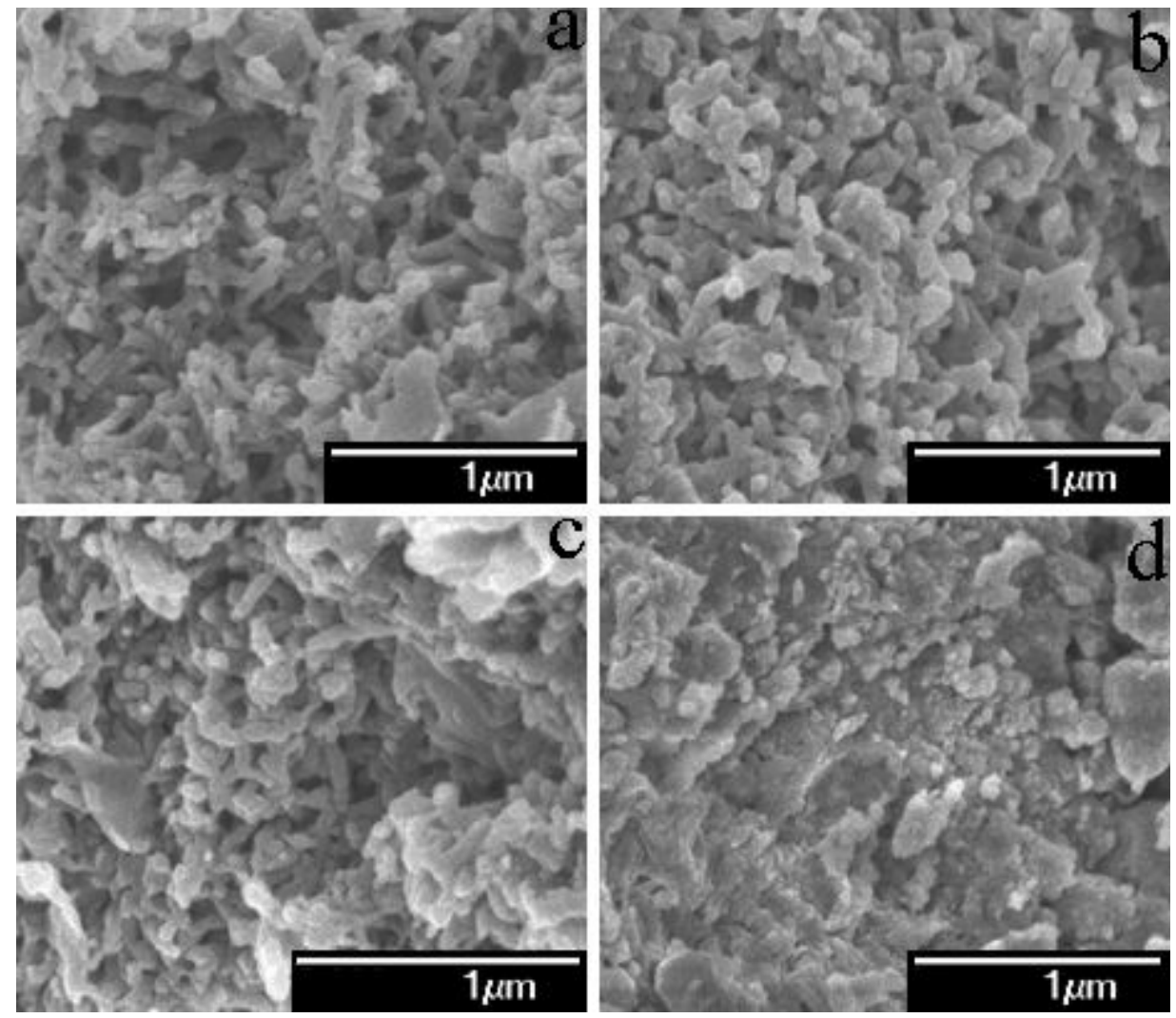

Fig. 2. SEM images of PANI obtained from the systems with different volumes of THF as additives (a-c) and without addition of organic solvent (d) (a. $0.2 \mathrm{~mL} ;$ b. $5 \mathrm{~mL}$; c. $10 \mathrm{~mL})$.

Addition of different volumes of organic solvent influences the morphology of the resulting PANI, as can be seen from Fig. 2. One can find when 0.2 or $5 \mathrm{~mL}$ of THF was added into the system, the PANI gave nanofiber morphology with average width from $40 \mathrm{~nm}(0.2 \mathrm{~mL})$ to $70 \mathrm{~nm}(5 \mathrm{~mL})$ and length keeping at about $500 \mathrm{~nm}$ (Fig. 2a and $2 \mathrm{~b}$, respectively), though some aggregates can be found. The increment of the diameter might be resulted from the improving interactions between the oligomer seeds when the usage of THF is increased. However, when the usage of THF was 
increased to $10 \mathrm{~mL}$, the resulting PANI showed serious aggregation, perhaps due to the poor dispersity of the oligomers produced at the early stage during the polymerization of aniline.

\section{UV-Vis spectra and dispersity in water}

A typical absorption spectrum of PANI has two absorption peaks at about $330 \mathrm{~nm}$ and $420 \mathrm{~nm}$ and one absorption peak maximum ( $\left.\lambda_{\max }\right)$ at about $850 \mathrm{~nm}$ (see Fig. 3). The first two peaks often combine to emerge as a platform. The peak at $330 \mathrm{~nm}$ arises from $\pi-\pi^{*}$ electron transition within benzenoid segments and the peak at 420 $\mathrm{nm}$, accompanied by the absorption with $850 \mathrm{~nm}$ as the maximum peak is related to the doping level and formation of polaron [9].

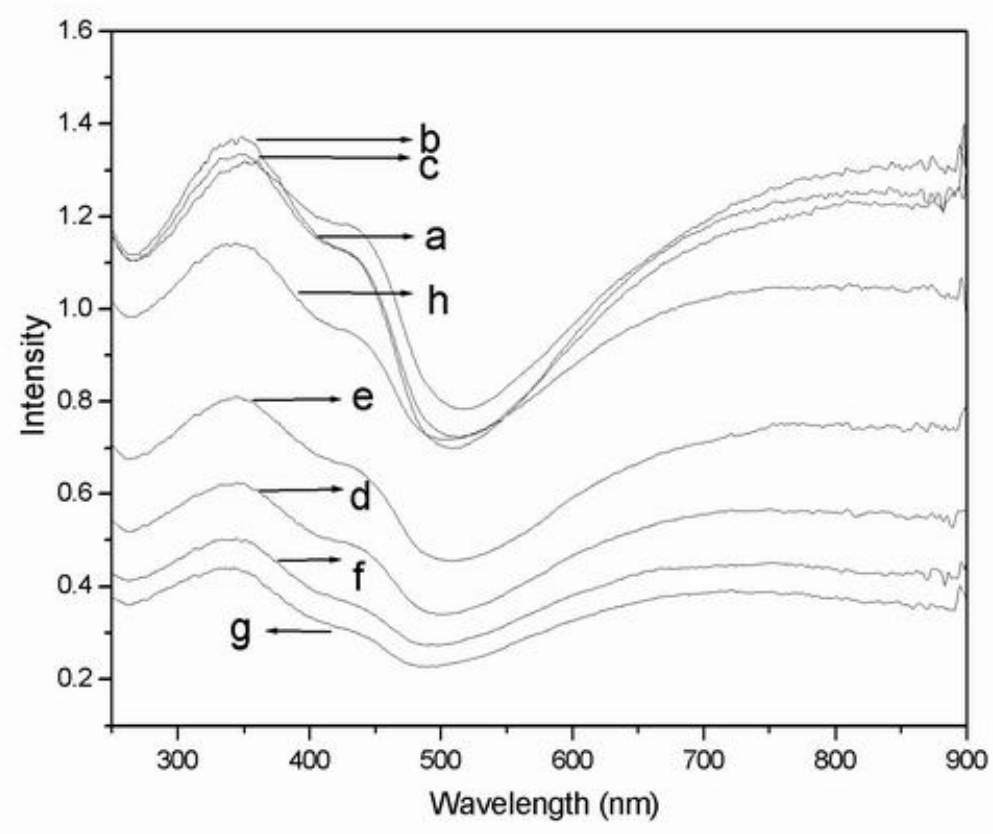

Fig. 3. UV-Vis spectra of PANI obtained from different systems for quantitative analysis (a. DMSO, $1 \mathrm{~mL}$; b. DMF, $1 \mathrm{~mL}$; c. THF, $1 \mathrm{~mL}$; d. NMP, $1 \mathrm{~mL}$; e. THF, 0.2 $\mathrm{mL}$; f. THF, $5 \mathrm{~mL}$; g. THF, $10 \mathrm{~mL}$; h. no organic solvent).

The dispersity of the samples in water can be reflected by the intensity of their UVVis absorption peaks, as shown in Fig. 3. Typically, the dispersions could be steady without apparent precipitate for at least $1 \mathrm{~h}$. Based on the quantitative analysis of the UV-Vis absorption of the samples, we found the dispersity of the PANI synthesized in the presence of $1 \mathrm{~mL}$ of DMSO, DMF and THF (Line a, b and c, respectively) was a bit better than that of the sample without addition of organic solvent (Line h). However, addition of NMP to the reaction system resulted in worst dispersity of the corresponding PANI (Line d). This may be originate from the fact that the more uniform the PANI is, the better dispersity it has. On the other hand, NMP has the strongest interaction with PANI among these four solvents, which perhaps impedes the dispersity of the resulting PANI. 
When the volumes of THF were changed, we found addition of $0.2,5$ and $10 \mathrm{~mL}$ of THF all resulted in poor dispersity of PANI in water. Except for the influence of the morphology, we think appropriate usage of THF is helpful for the dispersity of PANI in water because THF has weak $\mathrm{H}$-bond interaction with PANI and it can be partly dissolved in water. However, when more THF is added into the reaction system, the interaction between THF and PANI becomes stronger. On the contrary, the interaction between THF and water is weakened. Therefore, a poor water-dispersity is obtained in that case.

\section{FT-IR and Raman spectra}

The FT-IR spectra of the different samples are shown in Fig. 4. The presence of the characteristic peaks of PANI indicates the successful polymerization of aniline. For example, the peaks at ca. 1600 and $1500 \mathrm{~cm}^{-1}$ are assigned to $C=C$ stretching of the quinoid and benzenoid rings, respectively and the peak at ca. $1140 \mathrm{~cm}^{-1}$ represents the $\mathrm{C}-\mathrm{H}$ aromatic in-plane bending.

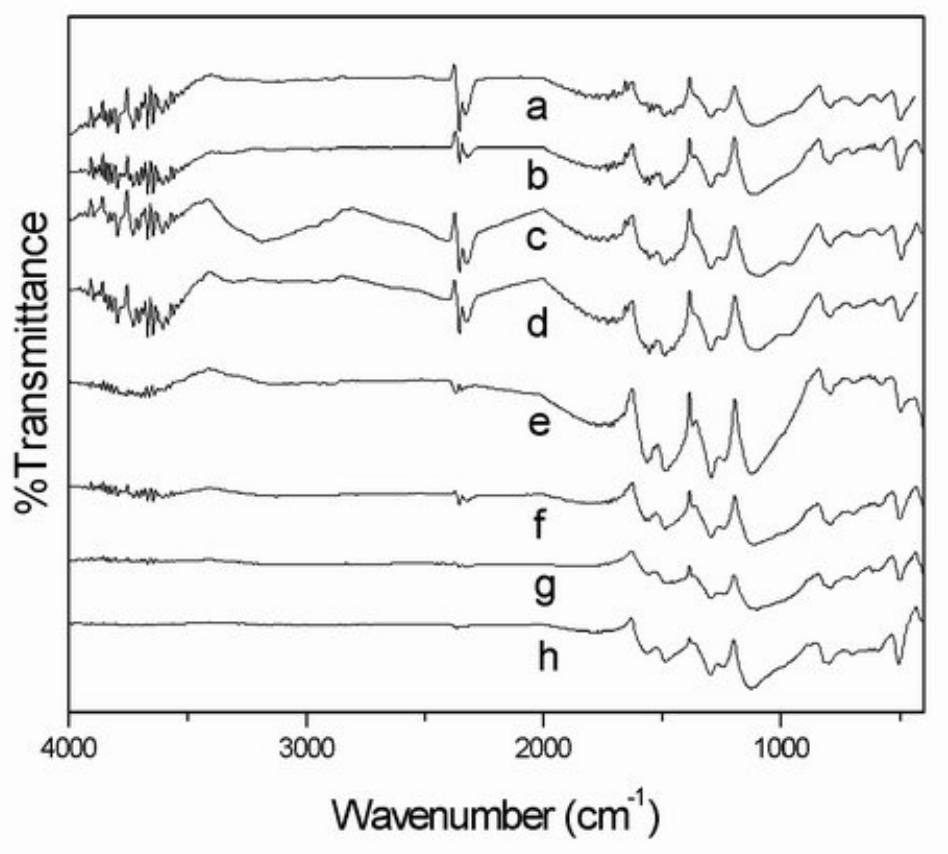

Fig. 4. FT-IR spectra of PANI obtained from different systems (a. DMSO, $1 \mathrm{~mL} ; \mathrm{b}$. DMF, $1 \mathrm{~mL}$; c. THF, $1 \mathrm{~mL}$; d. NMP, $1 \mathrm{~mL}$; e. THF, $0.2 \mathrm{~mL}$; f. THF, $5 \mathrm{~mL}$; g. THF, 10 $\mathrm{mL} ; \mathrm{h}$. no organic solvent).

The peak observed at $1292 \mathrm{~cm}^{-1}$ is related to the C-N stretching vibration of the benzenoid ring. The band which fall in the range of $800-860 \mathrm{~cm}^{-1}$ is identified with the out-of-plane bending of $\mathrm{C}-\mathrm{H}$ bond in the 1,4-disubstitued ring, which has been used as a key to identify the type of substituted benzene $[28,29]$. The peak at about 1140 $\mathrm{cm}^{-1}$ is often related to the doped structure; therefore, the results signify that the PANI obtained in the presence of organic solvents is more protonated than the conventional polymerized one, as can be seen from Table 1 . One can find the peak at $1135 \mathrm{~cm}^{-1}$ red-shifted to about $1124 \mathrm{~cm}^{-1}$ when the organic solvents were added into the system. However, excess addition of the organic solvent led the peak to the 
wavenumber as that of the PANI obtained by conventional method. This means that appropriate usage of organic solvents is helpful for the increase of the doping level of the resulting PANI.

Tab. 1. FTIR data of different samples.

\begin{tabular}{cccccc}
\hline Sample & \multicolumn{5}{c}{ Main peak position $\left(\mathrm{cm}^{-1}\right)$} \\
\hline $1^{*}$ & 800 & 1124 & 1294 & 1487 & 1553 \\
2 & 800 & 1123 & 1294 & 1485 & 1552 \\
3 & 794 & 1122 & 1292 & 1487 & 1552 \\
4 & 795 & 1127 & 1294 & 1485 & 1562 \\
5 & 792 & 1125 & 1294 & 1479 & 1562 \\
6 & 796 & 1137 & 1294 & 1485 & 1562 \\
7 & 815 & 1142 & 1296 & 1490 & 1568 \\
8 & 815 & 1135 & 1296 & 1485 & 1579 \\
\hline
\end{tabular}

* The number of the sample is related to that in Table 3.

The Raman spectra of the samples are presented in Fig. 5. The bands at about 1600 and $1400 \mathrm{~cm}^{-1}$ assigned to the $\mathrm{C}-\mathrm{C}$ stretching vibration of the benzenoid and quinoid rings can be observed. The bands at ca. 1500,1335 and $1167 \mathrm{~cm}^{-1}$ corresponding to the $\mathrm{C}=\mathrm{N}$ stretching of the quinoid diimine units, the $\mathrm{C}-\mathrm{N}$ stretching of the cation radical and the $\mathrm{C}-\mathrm{H}$ bending vibration, respectively, are also found.

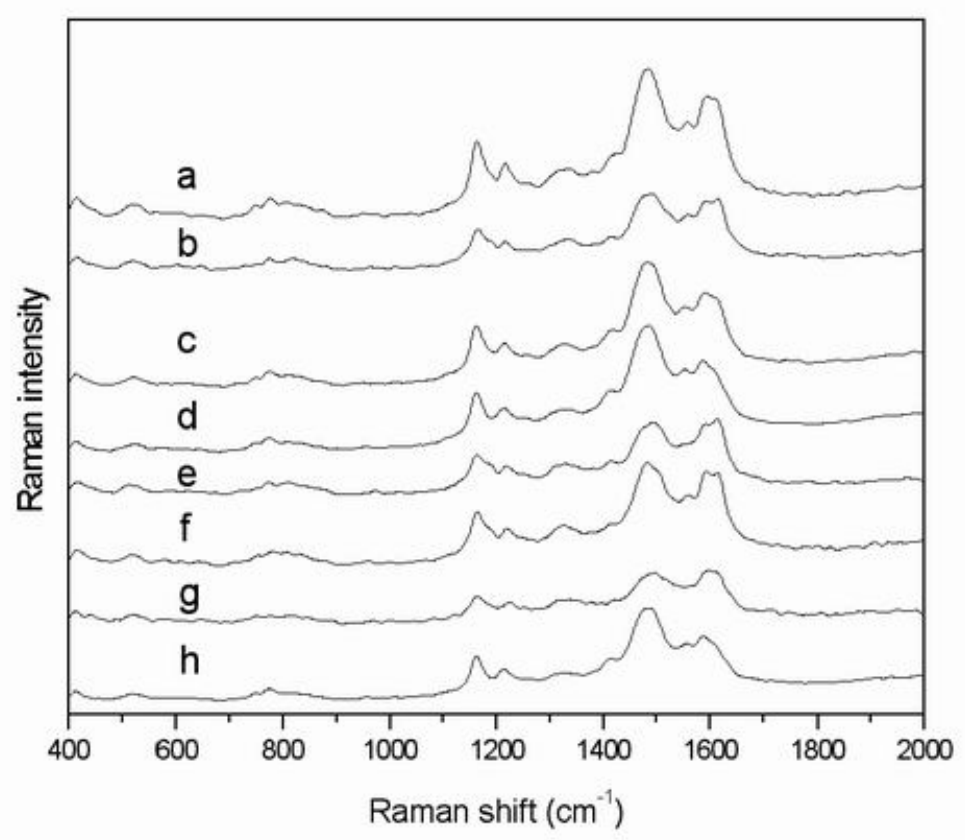

Fig. 5. Raman spectra of PANI obtained from different systems (a. DMSO, $1 \mathrm{~mL} ; \mathrm{b}$. DMF, $1 \mathrm{~mL}$; c. THF, $1 \mathrm{~mL}$; d. NMP, $1 \mathrm{~mL}$; e. THF, $0.2 \mathrm{~mL}$; f. THF, $5 \mathrm{~mL} ; \mathrm{g}$. THF, 10 $\mathrm{mL}$; h. no organic solvent).

The bands at about 800 and $417 \mathrm{~cm}^{-1}$ are related to the $\mathrm{C}-\mathrm{H}$ deformation, the band at $575 \mathrm{~cm}^{-1}$ is attributed to the amine deformation and the band at $525 \mathrm{~cm}^{-1}$ can be 
ascribed to the $\mathrm{C}-\mathrm{N}-\mathrm{C}$ torsion [27, 32]. Combining Fig. 5 with Table 2, we also find the peaks shift to lower wavenumbers when the organic solvents are added into the reaction systems, indicating the conjugation length of the PANI is extended or the PANI owned a higher doping level [33].

Tab. 2. Raman shifts of different samples.

\begin{tabular}{ccccccc}
\hline Sample & \multicolumn{5}{c}{ Main peak position $\left(\mathrm{cm}^{-1}\right)$} \\
\hline $1^{*}$ & 774 & 1162 & 1332 & 1419 & 1483 & 1593 \\
3 & 773 & 1162 & 1334 & 1417 & 1476 & 1592 \\
4 & 771 & 1163 & 1329 & 1419 & 1478 & 1592 \\
5 & 776 & 1161 & 1342 & 1417 & 1487 & 1593 \\
6 & 772 & 1162 & 1339 & 1420 & 1490 & 1592 \\
7 & 788 & 1162 & 1342 & 1416 & 1488 & 1596 \\
8 & 792 & 1165 & 1340 & 1420 & 1494 & 1600 \\
& 776 & 1162 & 1331 & 1417 & 1489 & 1592 \\
\hline
\end{tabular}

* The number of the sample is related to that in Table 3 .

\section{Conductivity}

Typically, the conductivity of the samples lies in two aspects: microscopic and macroscopic conductivity. The former depends on the doping level, conjugation length and chain length, etc., whereas the macroscopic conductivity is related to some external factors, such as the compactness of the samples [34].

Based on the UV-Vis, FT-IR and Raman spectra data, we can expect that the PANI obtained with addition of $1 \mathrm{~mL}$ of DMSO, DMF and THF may have higher conductivity owing to their higher conjugation lengths and doping levels. From Table 3, the conclusion can be confirmed that the samples synthesized in the presence of $1 \mathrm{~mL}$ of DMSO, DMF and THF show relatively high conductivity values of 5.31, 6.32 and 9.09 $\mathrm{S} / \mathrm{cm}$, respectively. However, the sample obtained from the system with addition of 1 $\mathrm{mL}$ of NMP has a lower conductivity value $(2.86 \mathrm{~S} / \mathrm{cm})$ than that from the system without organic solvent $(4.76 \mathrm{~S} / \mathrm{cm})$.

Tab. 3. Preparation conditions of PANI and the corresponding conductivity values.

\begin{tabular}{cccccc}
\hline Sample & $\begin{array}{c}\text { Aniline } \\
(\mathrm{M})\end{array}$ & APS (M) & Organic solvent & $\mathrm{HCl}(\mathrm{mL})$ & $\begin{array}{c}\text { Conductivity } \\
\text { (S/cm) }\end{array}$ \\
\hline 1 & 0.1 & 0.1 & DMSO, $1 \mathrm{~mL}$ & 49 & 5.31 \\
2 & 0.1 & 0.1 & DMF, $1 \mathrm{~mL}$ & 49 & 6.32 \\
3 & 0.1 & 0.1 & THF, $1 \mathrm{~mL}$ & 49 & 9.09 \\
4 & 0.1 & 0.1 & NMP, $1 \mathrm{~mL}$ & 49 & 2.86 \\
5 & 0.1 & 0.1 & THF, $0.2 \mathrm{~mL}$ & 49.8 & 2.79 \\
6 & 0.1 & 0.1 & THF, $5 \mathrm{~mL}$ & 45 & 1.18 \\
7 & 0.1 & 0.1 & THF, $10 \mathrm{~mL}$ & 40 & 0.56 \\
8 & 0.1 & 0.1 & $/$ & 50 & 4.76 \\
\hline
\end{tabular}

From Table 3 we can also find that addition of different volumes of organic solvent has influence on the conductivity of the resulting PANI. When only $0.2 \mathrm{~mL}$ of THF was added into the solution, the product gave a value of $2.79 \mathrm{~S} / \mathrm{cm}$, which was a bit lower than that of the PANI obtained by conventional method. Increasing the usage 
of THF to $1 \mathrm{~mL}$ led to a high conductivity value of $9.09 \mathrm{~S} / \mathrm{cm}$. However, excess addition of THF into the reaction solution resulted in the PANI with a lower value than that from the system without organic solvent (Samples 6 and 7 in Table 3). We consider that this originates from the common interactions of the microscopic and macroscopic factors, which can be found from their UV-Vis, FT-IR and Raman spectra and morphology.

\section{Conclusions}

Different kinds of organic solvents including DMSO, DMF, THF and NMP were added into the reaction systems during the polymerization of aniline in aqueous solutions. The resulting PANI showed relatively uniform nanofiber morphology with high conductivity. The $\mathrm{H}$-bond interaction between the organic solvents and the PANI might play an important role in forming and dispersing the PANI nanofibers. However, when the interaction turned strong, e.g., using NMP or excess usage of THF as additive agents, aggregation would be observed and the water-dispersity of the corresponding PANI became bad.

\section{Experimental Part}

\section{Materials}

Aniline was distilled under vacuum before use and other regents were used as received.

\section{Synthesis of PANI}

A typical experiment was carried out as follows: $0.47 \mathrm{~g}$ of aniline was dissolved in hydrochloride solution $(1 \mathrm{M})$. Then the organic solvent was dropped into the above solution under stirring. 5 min later, ammonium persulfate (APS) dissolved in $50 \mathrm{~mL}$ of hydrochloride solution $(1 \mathrm{M})$ was added into the mixture in a dropwise manner to initiate the polymerization of the aniline. The mixture was stirred at room temperature for $8 \mathrm{~h}$ and the resulting precipitate was collected by filtration. After the product was washed by deionized water and ethanol continuously, the product was dried under vacuum at room temperature for $48 \mathrm{~h}$. The detailed preparation conditions are listed in Table 3.

\section{Characterization}

The morphology of the resulting PANI was observed using a scanning electron microscopy (SEM, JEOL FESEM JEM-6700F) with gold coating.

Optical spectra of the samples were recorded on a UV-2550 UV-Vis spectrometer. The dispersity of the product in water was measured based on their corresponding UV-Vis spectra using quantitative analysis. The quantitative analysis was conducted as follows: $0.0100 \mathrm{~g}$ of sample was dispersed in $50.00 \mathrm{~mL}$ of deionized water under supersonic treatment for $3 \mathrm{~min}$. Deionized water was used as background for this measurement. Because the samples for measurement were prepared under exactly the same conditions, the degree of their dispersity in water could be reflected from the corresponding absorption intensity in their UV-Vis spectra.

FT-IR spectra of the different samples were measured on an FTIR-8400s (Shimadzu) spectrometer in the transmission mode. Standard $\mathrm{KBr}$ technique was applied. Resolution of the measurements was equal to $4 \mathrm{~cm}^{-1}$. 
Raman spectra were collected in backscattering geometry using a Renishaw Ramascope System 1000 equipped with an Olympus microscope. Excitation light from a diode laser $(\lambda=514.5 \mathrm{~nm})$ was focused on the samples surface through the microscope. The wavenumber was calibrated by comparing with $520 \mathrm{~cm}^{-1}$ Raman band of silicon wafer.

The conductivity of powder pellets at room temperature was measured by a typical four-probe method (SDY-5). For each value reported, at least three measurements were averaged.

\section{References}

[1] MacDiarmid A.G. Angew. Chem. Int. Ed. 2001, 40, 2581.

[2] Dimitrakopoulos C.D.; Malenfant P.R.L. Adv. Mater. 2002, 14, 99.

[3] Virji S.; Kaner R.B.; Weiller B.H. Chem. Mater. 2005, 17, 1256.

[4] Virji S.; Huang J.; Kaner R.B.; Weiller B.H. Nano. Lett. 2004, 4, 491.

[5] Wang J.; Chan S.; Carlson R.R.; Luo Y.; Ge G.; Ries R.S.; Heath J.R.; Tseng H.R. Nano. Lett. 2004, 4, 1693.

[6] Huang J.; Virji S.; Weiller B.H.; Kaner R.B. Chem. Eur. J. 2004, 10, 1314.

[7] Zhang D.H.; Wang Y.Y. Mat. Sci. Eng. B-Solid 2006, 134, 9.

[8] Dorey S.; Vasilev C.; Vidal L.; Labbe C.; Gospodinove N. Polymer 2005, 46, 1309.

[9] Xing S.X.; Chu Y.; Sui X.M.; Wu Z.S. J. Mater. Sci. 2005, 40, 215.

[10] Huang K.; Wan M. Chem. Mater. 2002, 14, 3486.

[11] Yang C.H.; Chih Y.K.; Cheng H.E.; Chen C.H. Polymer 2005, 46, 10688.

[12] Li G.C.; Pang S.P.; Peng H.R.; Wang Z.B.; Cui Z.L.; Zhang Z.K. J. Polym. Sci. Pol. Chem. 2005, 43, 4012.

[13] Lu X.F.; Yu Y.H.; Chen L.; Mao H.P.; Wang L.F.; Zhang W.J.; Wei Y. Polymer 2005, 46, 5329.

[14] Kim D.; Choi J.; Kim J.Y.; Han Y.K.; Sohn D. Macromolecules 2002, 35, 5314.

[15] Jing X.L.; Wang Y.Y.; Wu D.; She L.; Guo Y. J. Polym. Sci. Pol. Chem. 2006, 44, 1014.

[16] Jing X.L.; Wang Y.Y.; Wu D.; Qiang J.P. Ultrason. Sonochem. 2007, 14, 75.

[17] Li C.; Hatano T.; Takeuchi M.; Shinkai S. Chem. Commun. 2004, 4, 2350.

[18] Zhang X.; Manohar S.K. Chem Commun. 2004, 4, 2360.

[19] Zhang X.; Goux W.J.; Manohar S.K. J. Am. Chem. Soc. 2004, $126,4502$.

[20] Choi S.S.; Chu B.Y.; Hwang D.S.; Lee S.G.; Park W.H.; Park J.K. Thin Solid Films 2005, 477, 233.

[21] Chiou N.R.; Epstein A.J. Adv. Mater. 2005, 17, 1679.

[22] Huang J.; Virji S.; Weiller B.H.; Kaner R.B. J. Am. Chem. Soc. 2003, 125, 314.

[23] Huang J.; Kaner R.B. J. Am. Chem. Soc. 2004, 126, 851.

[24] Huang J.; Kaner R.B. Angew. Chem. Int. Ed. 2004, 43, 5817.

[25] Huang J.; Kaner R.B. Chem. Commun. 2006, 6, 367.

[26] Li D.; Kaner R.B. J. Am. Chem. Soc. 2006, 128, 968.

[27] Zhang L.J.; Wan M.X. Adv. Funct. Mater. 2003, 13, 815.

[28] Zhang L.J.; Long Y.Z.; Chen Z.J.; Wan M.X. Adv. Funct. Mater. 2004, 14, 693.

[29] Xing S.X.; Zhao C.; Jing S.Y.; Wang Z.C. Polymer 2006, 47, 2305.

[30] Kan J.Q.; Lv R.G.; Zhang S.L. Synth. Met. 2004, 145, 37.

[31] Kan J.Q.; Zhang S.L.; Jing G.L. J. Appl. Polym. Sci. 2006, 99, 1848.

[32] Pereira da Silva J.E.; de Faria D.L.A.; Córdoba de Torresi S.I.; Temperini M.L.A.

Macromolecules 2000, 33, 3077. 
[33] Liu Y.-C. Electroanalysis 2003, 15, 1134.

[34] Chen A.; Wang H.; Zhao B.; Li X. Synth. Met. 2003, 139, 411. 